\begin{tabular}{|l|l|l|l|l|l|}
\hline J. Tek. Ling & Vol. 12 & No. 2 & Hal. 225 - 231 & Jakarta, Mei 2011 & ISSN 1441-318X \\
\hline
\end{tabular}

\title{
ANALISIS INDEKS KUALITAS AIR LINGKUNGAN PERTAMBANGAN BATUBARA PT KPC SUBDAS SANGATTA KALIMANTAN TIMUR
}

\author{
Wage Komarawidjaja \\ Peneliti Ekotoksikologi Perairan \\ Pusat Teknologi Lingkungan - BPPT \\ wkwidjaja@scientist.com
}

\begin{abstract}
Water quality index (IKA) is one tool to quickly predict the environmental quality status of an ecosystem or region to obtaining an alternative of the future management. To analyze the status of these indices utilize only data of environmental parameters that have been established as a key parameter determining the IKA.

From the analysis of the mining area of PT KPC IKA with key parameters TDS, DO, $C O D$, nitrogen $(N)$ and phosphorus. $(P)$ derived from the water quality of agricultural ecosystems, industry/mines and residential showed an index value of less well with the category (54.6163) on the interval $40 \leq I K A<60$. The low index value is proportional to the low value of ecosystem quality index industry / mining IKA (I) with a value of 45.82 with categories of less well on the interval $40 \leq I K A<60$. Consider, that the index value of ecosystem quality residential IKA $(H)$ and agricultural ecosystem quality index IKA $(P)$ with good and excellent categories, then the ecosystem of industry / mining is the focus that needs to be considered for improved management efforts.
\end{abstract}

Key Words: Environmental quality index,Waterquality index, ecosystem, key parameters

\section{PENDAHULUAN}

\subsection{Latar Belakang}

Daerah Aliran Sungai (DAS) Sangatta di Kabupaten Kutai Timur Propinsi Kalimantan Timur, merupakan salah satu DAS dimana kegiatan penambangan batubara oleh PT Kaltim Prima Coal (KPC) dilakukan ${ }^{1)}$. Sedangkan gambaran karakteristik DAS Sangatta tersebut dapat dilihat pada Tabel 1 di bawah ini²).

Sungai Sangatta merupakan salah satu sungai besar yang berada di wilayah
Sangatta yang bermuara ke Selat Makasar. Beberapa anak sungai juga bermuara ke Sungai Sangatta, seperti Sungai Benumuda, Sungai Murung, Sungai Kedapat, Sungai Mandili, Sungai Kenyamukan, Sungai Villa, Lembah Bendili, Sungai Jorang, dan Sungai Tempadan ${ }^{2}$.

Saat ini Sungai Villa, Lembah Bendili, Sungai Jorang, dan Sungai Tempadan merupakan badan penerima air dari kawasan tambang PT. KPC yang pada akhirnya akan masuk ke aliran Sungai Sangatta 
dan bermuara di Selat Makasar. Untuk itu, pengertian Subdas Sangatta adalah meliputi sungai Sangatta dan anak sungai Sangatta yang menjadi penerima air dari kawasan tambang tersebut ${ }^{2}$. terhampar kolam pasca tambang dengan potensi sumberdaya air yang relative besar sebagaimana disajikan pada Tabel 2 , untuk dapat dimanfaatkan bagi berbagai peruntukkan ${ }^{2}$.

Tabel 1. Karakteristik DAS Sangatta

\begin{tabular}{|c|c|c|c|c|}
\hline & Nama DAS & Luas DAS (Ha) & Nama Sungai & Panjang Sungai (m) \\
\hline 1 & Sangatta & $377.492,01$ & $\begin{array}{l}\text { S. Banumuda } \\
\text { S. Sangatta } \\
\text { S. Santan }\end{array}$ & $\begin{array}{r}58.819,72 \\
159.287,94 \\
68.538,66\end{array}$ \\
\hline
\end{tabular}

Dikawasan ini, sebagai kawasan penambangan, selain dijumpai aktifitas penambangan, teredia fasilitas perkantoran, pemukiman karyawan dan lain-lain, juga dijumpai pula kolam sedimentasi seperti Kolam KNJ dan bekas kolam sedimentasi seperti Kolam S2 serta void atau cekungan bekas penambangan yang sudah terisi air seperti Kolam Sangatta North dan Kolam Surya yang dikemudian hari dapat dimanfaatkan ${ }^{2}$.

Kolam Sangatta North dan kolam Surya ini, merupakan kolam raksasa di bekas areal penambangan batubara yang telah digenangi air. Kolam ini merupakan kolam pasca tambang batubara peninggalan perusahaan penambangan batubara sebelum manajemen PT. KPC mengambil alih kegiatan penambangan di kawasan ini. Selanjutnya di Kawasan Tambang Subdas Sangatta ini, akan ada beberapa kolam pasca tambang yang terbentuk, sehingga pada akhir masa penambangan akan
Adanya kegiatan penambangan batubara di Subdas Sangatta ini, selain telah menciptakan kolam-kolam raksasa akibat galian tambang juga diperkirakan akan timbul tekanan terhadap ekosistem lingkungan Subdas Sangatta, akibat adanya perubahan struktur batuan yang diikuti dengan perubahan kualitas fisika dan kimia tanah serta air di sekitarnya. ${ }^{3)}$ Dampak negatif dikawatirkan akan muncul pada kecukupan pasokan air yang memenuhi kriteria baku mutu bagi kelangsungan kehidupan, karena proses pemulihan secara alam (self recovery) suatu ekosistem, memerlukan proses waktu yang cukup panjang dan bertahap. Oleh karena itu, untuk memperoleh gambaran kondisi kualitas lingkungan kawasan penambangan PT KPC di Subdas Sangatta, perlu adanya penelaahan secara cepat dengan memanfaatkan formula Indeks Kualitas Lingkungan, khususnya dari sisi gambaran kualitas air.

Tabel 2. Potensi Air Kolam Pasca Tambang

\begin{tabular}{|r|l|r|r|r|r|}
\hline No & \multicolumn{1}{|c|}{ Nama Kolam } & \multicolumn{1}{c|}{$\begin{array}{c}\text { Potensi Air }\left(\mathrm{m}^{3} /\right. \\
\text { tahun })\end{array}$} & $\begin{array}{c}\text { Potensi Air } \\
\text { Minimal } \\
\left(\mathrm{m}^{3} / \text { bulan }\right)\end{array}$ & $\begin{array}{r}\text { Potensi Air } \\
\text { Maksimal } \\
\left(\mathrm{m}^{3} / \mathrm{bulan}\right)\end{array}$ & $\begin{array}{r}\text { Pengambilan } \\
\text { Air }(10 \% \mathrm{dr} \\
\text { Potensi Mak)m }{ }^{3 / h a r i}\end{array}$ \\
\hline 1 & Kolam Porodisa & $681.088,0$ & $-16.167,9$ & $163.592,7$ & $10.413,0$ \\
2 & Kolam Surya & $4.282 .000,2$ & $-101.647,5$ & $1.028 .507,1$ & $65.466,5$ \\
\hline 3 & Kolam Pelikan & $26.267 .293,2$ & $-623.541,7$ & $6.309 .223,9$ & $401.594,7$ \\
4 & Kolam Bendili & $27.430 .818,5$ & $-651.161,9$ & $6.588 .694,7$ & $419.383,6$ \\
\hline 5 & Kolam Inul & $71.608 .455,4$ & $-1.699 .865,2$ & $17.199 .860,5$ & $1.094 .805,5$ \\
\hline
\end{tabular}




\subsection{Indeks Kualitas Air (IKA)}

Indeks Kualitas Air adalah merupakan bagian dari formula Indeks Kualitas Lingkungan (IKL), dimana IKL dinyatakan dengan nilai numerik yang diperoleh dari penjumlahan Indeks Kualitas Udara (IKU), Indeks Kualitas Air (IKA) dan Indeks Kualitas Lahan/Tanah (IKT) menjadi suatu nilai tunggal| ${ }^{4}$.

Selanjutnya Indeks Kualitas Air (IKA) dinyatakan sebagai penjumlahan dari nilai Indeks Parameter Kunci Kualitas Air pada masing-masing ekosistem (ekosistem Pertanian, Hunian dan Industri). Parameter kunci tersebut dapat bersifat fisik, kimia dan biologi ${ }^{4}$.

Lebih lanjut, ditetapkan suatu Nilai Indeks Kualitas Air yang berkisar antara $0-100$, dimana nilai IKA $=0$ menunjukkan kualitas lingkungan paling buruk sedangkan nilai IKA=100 menunjukkan kualitas lingkungan paling baik (sempurna) ${ }^{4}$.

\subsection{Tujuan}

Tujuan dari analisis Kualitas Air menggunakan formula Indeks Kualitas Air (IKA) di kawasan penambangan ini dimaksudkan untuk mendapat gambaran secara cepat kondisi lingkungan yang digambarkan oleh nilai Indeks Kualitas Air dari beberapa parameter kunci lingkungan perairan, sehingga diperoleh gambaran kawasan atau ekosistem yang sudah mengalami perbaikan dan yang perlu dikelola.

\section{METODOLOGI}

Untuk mengetahui kualitas lingkungan secara cepat, dilakukan kompilasi data sekunder dan pengambilan data primer beberapa parameter kunci lingkungan perairan pada ekosistem pertanian, industri/ tambang dan hunian, seperti parameter total partikel terlarut (TDS), Oksigen terlarut (DO), kebutuhan oksigen Kimiawi (COD), Nitrogen $(\mathrm{N})$, Fosfor $(\mathrm{P})$ dan mikroba .

\subsection{Peralatan dan Pengukuran Contoh Air}

Parameter kualitas air diukur menggunakan Chlorotec probe (Chlorotec, type AAQ1183, Alec Electronics) yang merekam secara langsung (in-situ) parameter kualitas air, seperti suhu, Turbiditas, dan $\mathrm{pH}$, sedangkan untuk parameter TSS, TDS, N, dan $\mathrm{P}$ diambil sampelnya untuk dianalisa di Laboratorium. ${ }^{5)}$

Tabel 3. Parameter Kunci Ekosistem Hunian, Industri Tambang dan Pertanian

\begin{tabular}{|c|c|c|c|c|c|c|c|c|c|c|c|}
\hline \multirow{2}{*}{ Parameter } & \multirow{2}{*}{ Satuan } & & & & \multicolumn{4}{|c|}{ Ekosistem Pertanian } & & & \\
\hline & & 1 & 2 & 3 & 4 & 5 & 6 & 7 & 8 & 9 & 10 \\
\hline TDS & $\mathrm{mg} / \mathrm{l}$ & 2090 & 2140 & 1880 & 1900 & 1960 & 1760 & 1680 & 2060 & 2000 & 1900 \\
\hline DO & $\mathrm{mg} / \mathrm{l}$ & 6,50 & 5,00 & 6,50 & 4,10 & 6,50 & 5,00 & 6,80 & 4,80 & 6,20 & 3,60 \\
\hline COD & $\mathrm{mg} / \mathrm{l}$ & $<5,570$ & $<5,570$ & 38.722 & $<5,570$ & $<5,570$ & $<5,570$ & $<5,570$ & $<5,570$ & $<5,570$ & 24.833 \\
\hline Total P & $\mathrm{mg} / \mathrm{l}$ & 0.010 & $<0,008$ & 0.013 & 0.010 & 0.013 & 0.008 & 0.013 & $<0,008$ & 0.011 & $<0,008$ \\
\hline Total N & $\mathrm{mall}$ & 0.701 & 0.345 & 0.678 & 0.490 & 0.534 & 0.477 & 0.449 & 0.349 & 0.357 & 0.719 \\
\hline
\end{tabular}

\begin{tabular}{|c|c|c|c|c|c|c|c|c|c|c|c|c|}
\hline \multirow{2}{*}{ Parameter } & \multirow{2}{*}{ Satuan } & \multicolumn{5}{|c|}{ Ekosistem Pertanian } & \multicolumn{3}{|c|}{ Ekosistem Industri } & \multicolumn{3}{|c|}{ Ekosistem Hunian } \\
\hline & & 11 & 12 & 13 & 14 & 15 & 16 & 17 & 18 & 19 & 20 & 21 \\
\hline TDS & $\mathrm{mgll}$ & 730 & 810 & 810 & 860 & 890 & 800 & 2080 & 350 & 4500 & 3600 & 5260 \\
\hline$D O$ & $\mathrm{mgll}$ & 6.6 & 4.9 & 6.8 & 3.58 & 6.8 & 4.1 & & & & & \\
\hline COD & $\mathrm{mg} / \mathrm{l}$ & $<5,570$ & $<5,570$ & $<5,570$ & $<5,570$ & $<5,570$ & $<5,570$ & $<5,570$ & $<5,570$ & $<5,570$ & $<5,570$ & $<5,570$ \\
\hline Total P & $\mathrm{mg} / \mathrm{l}$ & $<0,008$ & 0.01 & $<0,008$ & $<0,008$ & $<0,008$ & 0.010 & 0.011 & $<0,008$ & 0.011 & 0.031 & 0.010 \\
\hline Total $\mathrm{N}$ & $\mathrm{mgll}$ & 0.537 & 0.462 & 0.675 & 0.395 & 0.269 & 0.689 & 1.005 & 0.644 & 0.485 & 0.786 & 0.475 \\
\hline
\end{tabular}




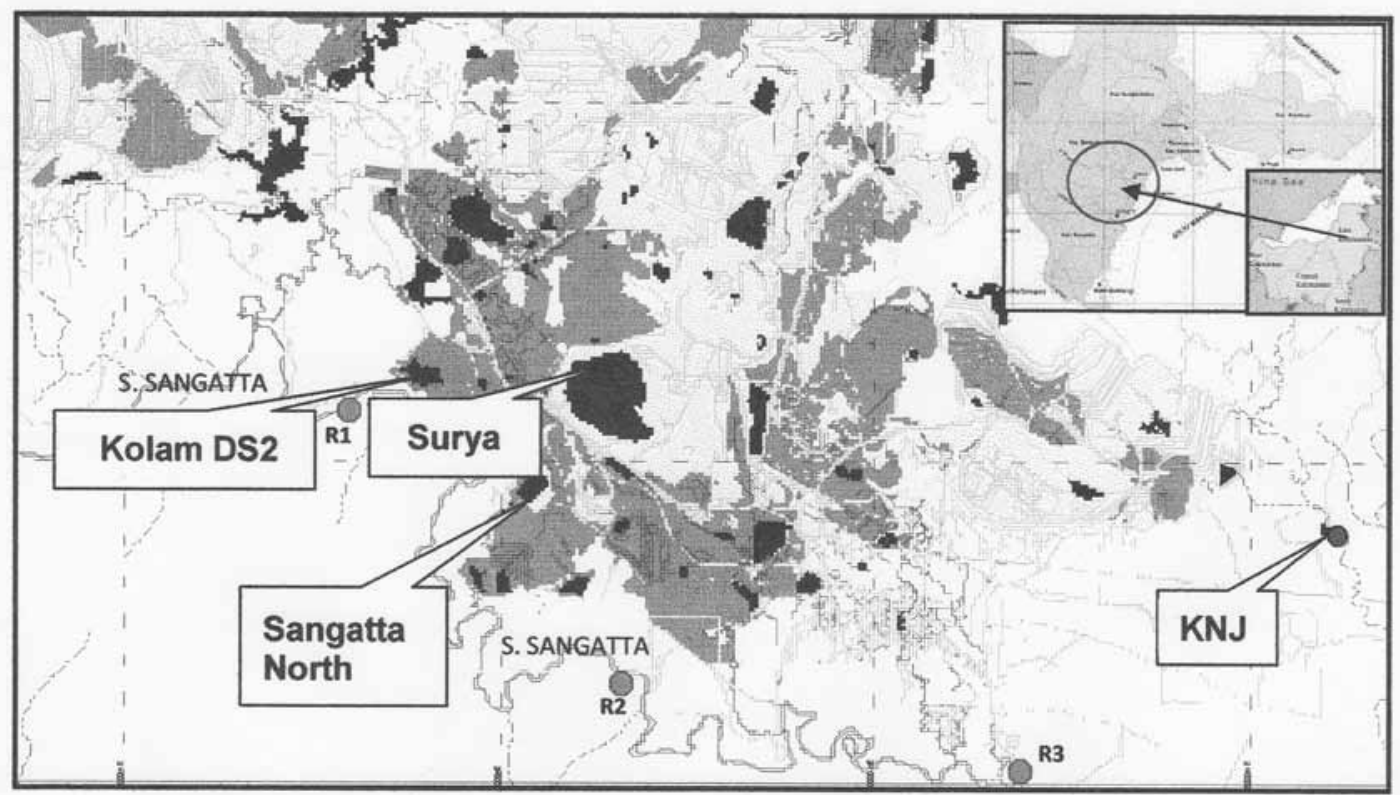

Gambar 1. Peta Sebaran Stasiun Sampel Parameter Kualitas Air di Kawasan Penambangan PT KPC, Subdas Sangatta

\subsection{Lokasi dan Hasil Pengukuran Contoh Air}

Lokasi contoh air dari Kolam bekas tambang (Kolam Surya dan Sangatta North) sebagai ekosistem pertanian, Kolam sedimentasi (KNJ dan DS2) sebagai ekosistem industri/tambang dan Sungai Sangatta ( R1, R2 dan R3) sebagai ekosistem hunian, disajikan pada peta Gambar 1. Data Parameter Kualitas Air disajikan pada Tabel 3.

\subsection{Analisa Data Kualitas Air}

Data kualitas air yang diperlukan untuk melakukan análisis kualitas Air dikelompokkan berdasarkan tipe ekosistem (Pertanian, Industri dan Hunian) dan dihitung dengan menggunakan formula Indeks Kualitas Air (IKA).

Selanjutnya dilalkukan analisis kualitas air dengan menggunakan formula Indeks Kualitas Air (IKA) sebagai berikut ${ }^{4)}$ :
$I K A \rightarrow$ ekosistem $=\sum_{i=1}^{n}(B i \times S i)$

$I K A=1288 \sum_{i=1}^{n}(B i p \times S i p)+2625 \sum_{i=1}^{n}(B i h \times S i h)+6061 \sum_{i=1}^{n}($ Bii $\times$ Sij)

Dimana:

IKA = Indeks Kualitas Matra Air

Bip= Bobot parameter Kualitas Air Ekosistem Pertanian

Bih= Bobot parameter Kualitas Air Ekosistem Hunian

Bii = Bobot parameter Kualitas Air Ekosistem Industri

Sip $=$ Skoring parameter Kualitas Air Ekosistem Pertanian

Sih= Skoring parameter Kualitas Air Ekosistem Hunian

Sii $=$ Skoring parameter Kualitas Air Ekosistem Industri 


\section{HASIL DAN PEMBAHASAN}

\subsection{Hasil Analisis Data Kualitas Air}

Dari hasil pengelompokan data kualitas air berdasarkan ekosistem Pemukiman atau Hunian $(\mathrm{H})$, Industri, Tambang (I) dan Pertanian $(P)$ disajikan pada Tabel 3 , dilanjutkan dengan penyusunan skor dan bobot dari masing masing parameter kualitas air tersebut, seperti dicantumkan pada Tabel 4.

Tabel 4. Skoring dan Pembobotan Parameter Kualitas Air

\begin{tabular}{|c|c|c|c|c|c|c|}
\hline Parameter & \multicolumn{2}{|c|}{ Pemukiman } & \multicolumn{2}{c|}{ Pertanian } & \multicolumn{2}{c|}{ Industri Tambang } \\
\cline { 2 - 7 } Kunci & SKOR & BOBOT & SKOR & BOBOT & SKOR & BOBOT \\
\hline TDS & 686.53 & 4.5 & 53.340 & 17.3 & 66.18 & 5.1 \\
\hline DO & 0 & 32 & 80.320 & 9.9 & 0 & 35.2 \\
\hline COD & 97.39 & 14.6 & 92.9 & 5.2 & 97.39 & 25 \\
\hline Total P & 102.81 & 8.4 & 103.32 & 28.8 & 103.33 & 9.4 \\
\hline Total N & 102.48 & 8.4 & 102.63 & 28.8 & 102.02 & 8.9 \\
\hline
\end{tabular}

Dari data skor dan bobot yang disajikan pada Tabel 4, dengan rumus IKA ekosistem dapat dihitung, Indeks Kualitas Air masing masing ekosistem (IKA-ekosistem) pada kawasan Subdas Sangatta, Kalimantan Timur.

Hasil komputasi nilai IKA ekosistem tersebut menunjukkan bahwa $\operatorname{IKA}(P)>$ $\operatorname{IKA}(\mathrm{H})>\operatorname{IKA}(\mathrm{I})$. dengan nilai masibngmasing indeks sebagai berikut: IKA ekosistem Pertanian atau IKA(P) adalah 81.32, IKA ekosistem Hunian atau IKA $(\mathrm{H})$ adalah 61.73 dan IKA ekosistem Industri atau IKA(I) adalah 45.82 , sebagaimana disajikan pada Tabel 5.

Selanjutnya, dari perhitungan IKA masing masing ekosistem, dilakukan komputasi untuk nilai IKA Kawasan Penambangan di Subdas Sangatta dengan menggunakan formula sebagai berikut :
$I K A=1288 \sum_{t=1}^{n}(B i p \times S i p)+2625 \sum_{i=1}^{n}(B i / \propto S i h)+6061 \sum_{i=1}^{n}(B i \dot{x} \times S i i)$

atau

$$
\begin{gathered}
\text { IKA }=12.88 * \operatorname{IKA}(P)+626.52 * \operatorname{IKA}(H) \\
+60.61 * \operatorname{IKA}(I)
\end{gathered}
$$

Berdasarkan hasil komputasi, nilai IKA kawasan Subdas Sangatta adalah 54.6163, sebagaimana disajikan pada Tabel 5. Nilai Indeks tersebut merupakan hasil penjumlahan Indeks Hunian, industri tambang dan Pertanian yang sudah dikalikan dengan masing masing koefisiennya.

\subsection{Status Indeks Kualitas Air}

Untuk menentukan status Indeks Kualitas Air kawasan Pertambangan PT KPC di Subdas Sangatta tersebut ditetapkan berdasarkan kriteria sebagai berikut :

a) Nilai perhitungan berkisar : $80 \leq$ $\mathrm{IKL} \leq 100$ dikatakan sangat baik, artinya kegiatan pembangunan sudah memperhatikan kaidah dayadukung lingkungan. Hal ini dapat mencerminkan jaminan peningkatan kesejahteraan tanpa merusak kondisi kualitas lingkungan ${ }^{4}$.

b) Nilai perhitungan berkisar : $60 \leq \mathrm{IKL}$ $<80$ dikatakan baik, artinya kegiatan pembangunan pada umumnya sudah berwawasan lingkungan, namun demikan masih ada beberapa sektor pembangunan yang harus tetap dipantau perkembangannya, apakah cenderung merusak lingkungan atau tidak $^{4}$.

c) Nilai perhitungan berkisar: $40 \leq \mathrm{IKL}$ $<60$ dikatakan Kurang baik , artinya kegiatan pembangunan yang bertumpu pada sumberdaya alam telah berakibat pada semakin menurunnya kaulitas lingkungan. Sehingga perlu segera dilakukan pengendalian dan pemulihan pada sektor-sektor yang merusak lingkungan ${ }^{4)}$. 
Tabel-5. Hasil Perhitungan Indeks Kualitas Air Kawasan Penambangan DAS Sangatta, Kalimantan Timur.

\begin{tabular}{|c|c|c|c|c|c|c|c|c|}
\hline No. & Ekosistem & IKA (I) & IKA (H) & IKA (P) & Koefisien I & Koefisien H & Koefisien P & \\
\hline 1 & Industri & 45.82 & - & - & 60.61 & - & - & 27.77 \\
\hline 2 & Hunian & - & 61.73 & - & - & 26.52 & - & 16.37 \\
\hline 3 & Pertanian & - & - & 81.32 & - & - & 12.88 & 10.47 \\
\hline \multicolumn{8}{|c|}{ Total Nilai IKA } & \\
54.61 \\
\hline
\end{tabular}

d) Nilai perhitungan berkisar $0 \leq \mathrm{IKL}$ $<40$ dikatakan Tidak baik, artinya mayoritas sumberdaya pembangunan telah diekspliotasi dengan cara yang tidak mengindahkan kaidah lingkungan, sehingga pengambil kebijakan perlu segera melakukan reorientasi dan peninjauan ulang strategi dan kebijakan pembangunannya ${ }^{4}$.

Berdasarkan kriteria penetapan Indeks, kawasan penambangan di Subdas Sangatta dengan nilai IKA 54.6163 termasuk pada kategori kurang baik karena memiliki nilai berkisar $40 \leq \mathrm{IKA}<60$. Dengan besaran nilai tersebut, artinya kegiatan yang bertumpu pada penambangan sumberdaya alam telah berakibat pada semakin menurunnya kaulitas lingkungan. Sehingga perlu segera dilakukan pengendalian dan pemulihan pada sektor-sektor yang merusak lingkungannya ${ }^{4}$.

Untuk mengetahui, pada tataran mana penanganan lingkungan harus dilakukan, telaah dilanjutkan dengan memeriksa nilai Indeks pada tataran ekosistem, apakah ekosistem hunian, ekosistem industry tambang atau ekosistem pertanian yang harus dilakukan pembenahan.

Dari hasil analisis IKA tataran ekosistem, ternyata nilai indeks ekosistem pertanian IKA (P) memiliki nilai paling besar (81.32), termasuk pada kategori sangat baik karena memiliki nilai berkisar $80 \leq \mathrm{IKA}<100$, sedangkan nilai indeks ekosistem hunian IKA (H) memiliki nilai 61.73, yang termasuk pada kategori baik karena memiliki nilai berkisar $60 \leq \mathrm{IKA}<80$,

Nilai IKA $(P)$ yang tinggi artinya kualitas lingkungannya ekosistem pertanian masih sangat baik. Kondisi tersebut tidak jauh berbeda dengan kajian status kualitas lingkungan kolam Sangatta North dan kolam Surya yang dinyatakan masih memenuhi standar baku mutu air kelas I dan II (Kolam Sangatta North), kelas III dan IV (Kolam Surya) $)^{6,7,8)}$.

Sedangkan untuk nilai IKA $(\mathrm{H})$ meskipun masuk dalam kategori baik, tapi dari segi kualitas fisik, masih memerlukan penanganan dalam pemanfaatan sumber air, karena dari observasi lapang masih menunjukkan kekeruhan yang tinggi (turbidity, TDS dan TSS).

Sebaliknya hasil analisis IKA tataran ekosistem, industri tambang atau IKA (I) menunjukkan nilai paling kecil (45.82) dan masuk pada kategori kurang baik karena memiliki nilai berkisar $40 \leq \mathrm{IKA}<60$. Dengan demikian, kualitas air ekosistem industri tambang yang digambarkan oleh kolam sedimentasi KNJ, DS2 dan kolam sedimentasi lainnya, pengelolaannya perlu ditingkatkan, sehingga air kolam sedimentasi tersebut menjadi lebih baik sebelum dialirkan ke ekosistem lain menuju perairan terbuka (sungai dan laut).

Dengan demikian dapat dikatakan, bahwa kawasan penambangan PT KPC di Subdas Sangatta, menunjukkan nilai IKA yang kurang baik, khususnya pada ekosistem kegiatan tambang yang diwakili oleh nilai IKA (I).

\section{PENUTUP}

Hasil pengelompokan data ekosistem di kawasan tambang PT KPC kedalam 
eksistem pertanian, industry/tambang dan hunian, menunjukkan: (1) nilai IKA kawasan penambangan yang kurang baik (54.6163), (2) rendahnya nilai IKA kawasan penambangan tersebut dipengaruhi oleh rendahnya nilai IKA (I) ekosistem Industri/tambang (45.82), (3) perhitungan dengan formula IKA ini dapat membantu menunjukkan ekoisitem mana yang perlu mendapat prioritas pengelolaan.

\section{DAFTAR PUSTAKA}

1. .......... 2009. Peta Administrasi Kabupaten Kutai Timur. http:// id.wikipedia.org/Berkas:Locator Kutim. ipg

2. .......... 2009. Laporan Akhir Studi Pemanfaatan Air Kolam (Void Water) Pasca Tambang PT. Kaltim Prima Coal Sangatta - Kalimantan Timur. PTL BPPT.

3. ..........2009. Sustainability Through the Global Financial Crisis. Sustainability Report. PT Kaltim Prima Coal. Sangatta, Kutai Timur, Kalimantan Timur.
4. Anonymous. 2006. Laporan Akhir (Final Report) Studi Penyusunan Indeks Kualitas Lingkungan (IKL). Badan Perencanaan Pembangunan Nasional (Bappenas)

5. APHA. 1995. Standard methods. 19th Edition. American Public Health Association. Washington DC.

6. Komarawidjaja, W. 2009. Status Kualitas Perairan Kolam Sangatta North Bekas Kolam Sedimentasi Tambang Batubara di Kalimantan Timur. Jurnal Hidrosfir Indonesia, PTLBPPT 4(1):29 - 35

7. Komarawidjaja, W. 2011. Status Ekosistem Lingkungan Void Surya, Kolam Pasca Penambangan Batubara Di Kalimantan Timur. Jurnal Hidrosfir Indonesia, PTL-BPPT 6(1):

8. Santoso, A D, dan W Komarawidjaja. 2009. Tinjauan Limnologi Danau Buatan Bekas Tambang Studi kasus Danau Sangatta North di Kalimantan Timur. Jurnal Hidrosfir Indonesia, PTLBPPT 4(3):153 - 159 